\title{
Classification of Adolescent Offenders of the Law with Radial Neural Network Bases Function
}

\author{
Víctor Daniel Gil Vera ${ }^{1}$, Catalina Quintero López ${ }^{2}$, Isabel Cristina Puerta Lópera ${ }^{3} \&$ Gabriel Jaime Correa Henao $^{4}$ \\ ${ }^{1}$ Facultad de Ingenierías y Arquitectura, Universidad Católica Luis Amigó, Medellín, Colombia \\ ${ }^{2}$ Facultad de Psicología, Grupo NBA, Universidad Católica Luis Amigó, Medellín, Colombia \\ ${ }^{3}$ Vicerrectoría de Investigaciones, Grupo NBA, Universidad Católica Luis Amigó, Medellín, Colombia \\ ${ }^{4}$ Sedic S.A, Ingenieros Consultores, Medellín, Colombia \\ Correspondence: Víctor Gil, Facultad de Ingenierías y Arquitectura, Universidad Católica Luis Amigó, Medellín, \\ ON., M3A 2K7, Colombia. E-mail: victor.gilve@ amigo.edu.co
}

$\begin{array}{ll}\text { Received: February 1, } 2019 & \text { Accepted: September 16, } 2019 \quad \text { Online Published: September 17, } 2019 \\ \text { doi:10.5539/mas.v13n10p39 } & \text { URL: https://doi.org/10.5539/mas.v13n10p39 }\end{array}$

The research is financed by Universidad Católica Luis Amigó

\begin{abstract}
Radial Basis Function Neural Networks (RBFNN) are a type of artificial neuronal network (ANN) that estimate the output of the function taking as a reference the distance to a point called center. This paper presents a RBFNN for the classification of adolescents' offenders of the law according to their dangerousness level, that have been admitted to the Specialized Attention Center (SAC), "El Redentor" in Bogotá, Colombia in the year 2017. This classification may be utilized by psychosocial teams of the SAC in order to customize and make more effective the therapeutic pedagogical treatment. The ANN developed is particularly good for identifying adolescents with a high, low and null dangerousness level.
\end{abstract}

Keywords: artificial intelligence, criminal dangerousness, drugs, neural networks, young offenders

\section{Introduction}

The psychosocial teams of the Specialized Attention Centers (SAC) administered by the Congregation of Capuchin Tertiary Religious, currently perform rehabilitation of adolescents deprived of their liberty in several Colombian cities, including Bogotá. The therapeutic pedagogical intervention process covers the following areas: pedagogical, psychological, partner, family health, spiritual, academic and cultural attention. Such intervention is carried out at all levels of the therapeutic and pedagogy process: reception, channeling, reinforcement and strengthening from the income of the adolescent until his discharge. The development of this paper arises from the confusion that is presented in the SAC at the time to classify adolescents according to their condition and dangerousness level (schooling level, murderer, multi-addict, LGBTI, etc.) situation which made it impossible to provide a personalized treatment to adolescents who have conditions of greater severity at time of admission.

The study of the danger of a person is a matter dependent on the forensic psychiatry provided that such alleged danger arising from mental illness (González, 2010). The first steps of the criminal career started at early ages. In this way, adolescence is a key period for the implementation of preventive programs of antisocial and criminal behavior (Vilariño, Amado, \& Alves, 2013). Dangerousness means quality of dangerous and more narrowly, criminal dangerousness is the tendency of a person to commit a crime evidenced usually over its antisocial behavior (Rodríguez, 2003). The diagnosis of danger (probability or risk) is not easy, due to the possibility of predicting validly a type of human behavior and the relatively subjective to the very concept of dangerousness. At first sight, the assessment of the dangerous criminal would follow the next supposition: a man who has committed an offense would be insignificant little dangerous; another, on the contrary it has committed a serious offense would be very dangerous (Rodríguez, 2003). Despite all the classic studies that have been conducted since the last century, has not found a structured type of personality criminal, but we can obtain a series of personality traits, which are more frequent among groups of criminals demonstrably dangerous (impulsivity, low self-esteem, suspicion, psychoses or hardness). However, this approach defines a collective, not to a specific 
individual "dangerous". In the psychological analysis of dangerousness is traditional go to two instances:

- Analysis of the personality: constitutional factors, upbringing, traits or provisions, deficiencies

- Analysis of the dangerous situations, i.e. the opportunity to commit a crime is present and there is a dynamic factor, the impulse toward crime (aggressiveness, mental disorder, bad control of anger, alcoholism)

The consumption of alcohol is analyzed as an integral part of youth culture, stripping the explanation of moralist contents, and approaching the conception that the consumption of alcohol is a medium that uses the adolescent to achieve its setting in a society that is characterized by the complexity (Pons \& Buelga, 2011). The relationship between violence and the mental status of offenders has become an important clinical and social issue (Eccleston \& Ward, 2004). Mental illness is common among detained youth, and treating them effectively might mean changing the juvenile justice system (Alcorn, 2016). The people with mental illness are somehow less in control of their actions than those without such illness (Peay, 2009). Criminal responsibility within the law pertains to the criteria necessary to determine criminal liability. Attributions of criminal responsibility are based on the assumption that the offender has violated societal norms; thus, individuals who are deemed incompetent to uphold these norms are exonerated from criminal responsibility (Eccleston \& Ward, 2004). In modern prisons, many prisoners are young, members of a minority group, and undereducated. About half of prisoners are violent offenders (Pollock, 2012).

Many adolescents' offenders of the law have psychopathy, a cluster of affective, interpersonal, and behavioral characteristics (Eccleston \& Ward, 2004). Typically, a psychopath exhibits glibness and superficial charm; lack of empathy, guilt, and remorse; egocentricity; selfishness, deceitful, and manipulative behavior; impulsive and irresponsible behavior; and a lack of interpersonal attachments (Eccleston \& Ward, 2004). The socio educational intervention can be defined as the set of actions carried out by a group of professionals on the adolescent offenders of the law belonging to SAC (Ochoa, 2014). These actions aim to achieve their rehabilitation so that they can improve their behavior and reintegrate into society as civilized people. The intervention process in the SAC covers the following areas: pedagogical, psychological, partner, family health, spiritual, academic and cultural (Ochoa, 2014).

The objective of this paper is to develop an Artificial Neural Network (ANN) that meets the requirements of the psychosocial teams, so they are able to classify adolescents who enter the centers according to their dangerousness level (high, medium, low and null). Such classification may be useful in the customization of the therapeutic pedagogical treatment, and therefore, it leads to a better efficiency on the rehabilitation process. The psychosocial teams to know the criminal characteristics, consumption trends and family problems, can customize the types of treatments that apply to adolescents who enter the SAC, situation that can facilitate and make easier the rehabilitation process. H1: The classification of adolescent offenders of the law according to their physical, psychological and socio-economic conditions at the time of entry into the SAC, facilitates the rehabilitation process.

It was decided to use an RBFNN for modeling the problem because you can include variables that are difficult to quantify through simple equations, which allows to consider specific conditions of adolescents as civil status, schooling level, and incomes, etc. Finally, authors show that the proposed RBFNN model is good to identify adolescents with a high, low and null dangerousness level.

\section{Method}

The RBFNN are a type of artificial neural networks (ANN) that calculate the output as a function of distance from a point called center. The basic topology of RBFNN comprises an input layer, a hidden layer and an output layer formed by linear processing units (Arliansyah \& Hartono, 2018; Guan, Zhu, \& Song, 2016; Gubana, 2018). A typical RBFNN configuration is shown in Figure 1 for a single output, where the outputs of the nonlinear activation are combined linearly with the weight vector $\beta$ of the output layer to produce the network. 
Input Layer

Hidden layer

Output Layer

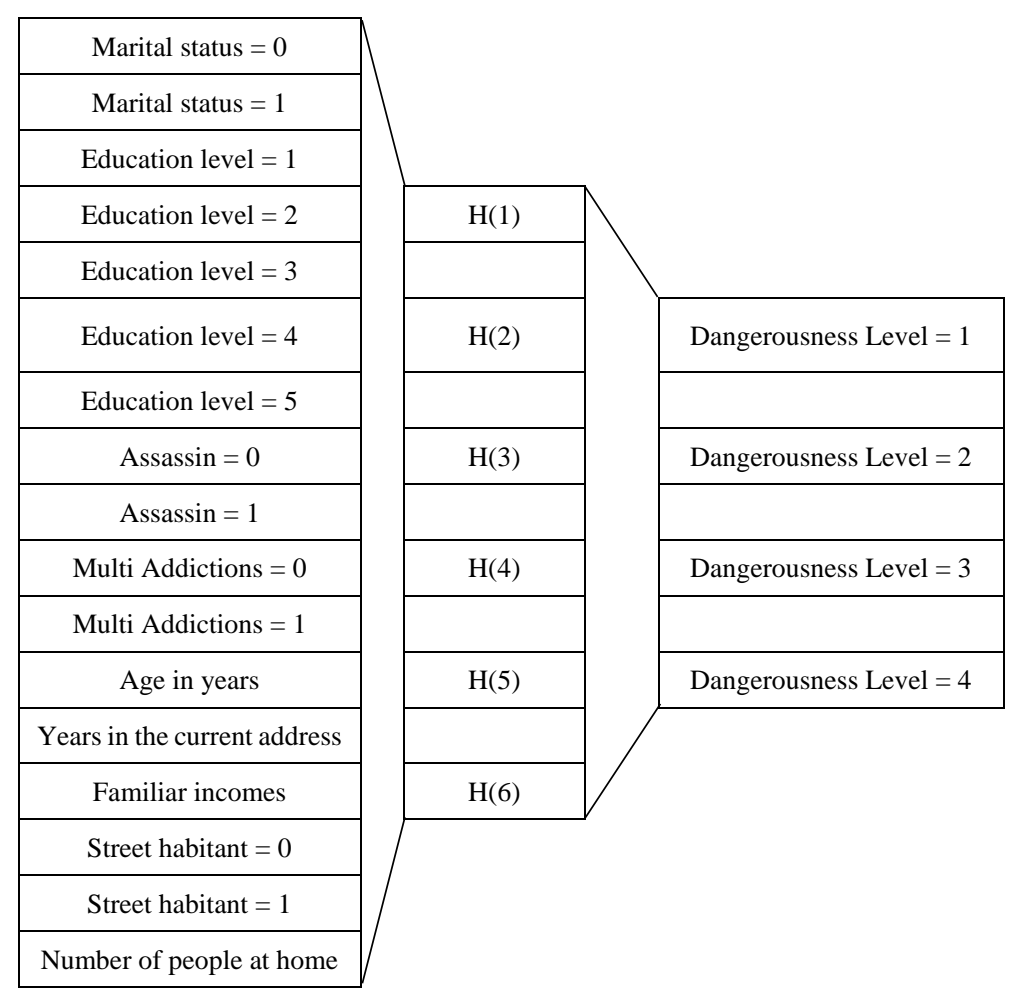

Figure 1. RBFNN structure

In the topology of networks, a RBFNN is similar to a special case of multilayer feedforward neural networks, but different in terms of node characteristics and learning algorithm (Arliansyah \& Hartono, 2018). Radial basis function (RBF) networks have advantages of easy design, good generalization, strong tolerance to input noise, and online learning ability (Yu \& Xie, 2011).

$$
f(x)=\sum_{i=1}^{r} w_{i} \phi_{i}\left(\left|X-\mu_{i}\right|, \phi_{i}\right)
$$

Where $\mathrm{X} \in R^{n}$ is an input vector, $\phi i$ is the basis function of the network from $R^{n}$ to $R$, wi are weights of the network is called the center vector of the $i$-th node is called the bandwidth vector of the $i$-th node denotes the Eucliden node. The training of RBF neural network is accomplished through the estimation of three kinds of parameters, namely the centers and the widths of the radial basis functions and the neuron connection weights (Guan et al., 2016). RBFNN networks form a special architecture of neural networks that present important advantages compared to other neural network types, including simpler structure and faster learning algorithms (Moody and Darken, 1988, Darken and Moody, 1990 and Binchini et al., 1995). RBF is a feedforward neural network model with good performance and it has already proved its universal approximation ability with no local minima problem (Binchini et al., 1995). An RBF has a single hidden layer. Each node of the hidden layer has a parameter vector called center. This center is used to compare with the network input vector to produce a radially symmetrical response. Responses of the hidden layer are scaled by the connection weights of the output layer and then combined to produce the network output (Iliyas, Elshafei, Habib, \& Adeniran, 2013). In the neural networks systems is important the statistical transformation of input data (Henao \& Suárez, 2013).

The RBFNN procedure allows you to generate a predictive model for one or more dependent variables based on the values of the predictive variables. Classified the database of adolescent offenders who entered to the SAC "El Redentor" in the year 2017, by categorizing the adolescents in four groups according to the dangerousness level (high, medium, low and null). If the adolescent's data can be used to predict the belonging to a group, you can customize the therapeutic pedagogical treatment for each possible adolescent offender of the law.

A search of literature reviews, articles, conference proceedings, abstracts and publications was developed in specialized databases. In addition, we reviewed articles published in the following journals: International Journal of Offender Therapy and Comparative Criminology, Journal of Interpersonal Violence, Criminal Behaviour and 
Mental Health and Behavioral Sciences and the Law. The range of dates was understood from the year 2010 until the year 2017. The keywords used were: neural networks, criminal dangerousness, young offenders, artificial intelligence, specialized attention centers and drugs. Search equations used were:

(TITLE-ABS-KEY (RBFNN) OR (criminal dangerousness) AND (((young offenders) OR (((artificial intelligence) OR ((specialized attention centers) OR (drugs)))) >2009

(TITLE-ABS-KEY (RBFNN) AND (criminal dangerousness) AND (((young offenders) AND (((artificial intelligence) AND ((specialized attention centers) AND (drugs)))) >2009

(TITLE-ABS-KEY (RBFNN) AND (criminal dangerousness) AND (((young offenders) OR (((artificial intelligence) AND ((specialized attention centers) OR (drugs)))) >2009

(TITLE-ABS-KEY (RBFNN) AND (criminal dangerousness) AND (((young offenders) AND (((artificial intelligence) AND ((specialized attention centers) OR (drugs)))) >2009

(TITLE-ABS-KEY (RBFNN) OR (criminal dangerousness) OR (((young offenders) OR (((artificial intelligence) OR ((specialized attention centers) AND (drugs $))))>2009$

In the review of the state of the art should not be found related jobs in which used artificial neural networks ANN to classify criminals or adolescent offenders of the law. In the construction of the network was employed a database with the information of 616 adolescents that entered to the SAC 'El Redentor' in Bogotá - Colombia in 2017, was employed a Radial Basic Function Neural Network (RBFNN) in the statistical software IBM SPSS (Plume, 2003), was developed a predictive model for the dependent variable (dangerousness level) based on the predictor variable values: marital status, schooling level, psychoactive substances, number of homicides, age in years, number of persons living with him/her, monthly family incomes and number of months living in the street. For the construction of the network was used the Radial Basis Function (RBF) in the statistical software IBM SPSS. The database was composed by the following fields: level of dangerousness (high, medium, low, null), marital status (single, married, union free, separate), educational level (primary full/incomplete, baccalaureate full/incomplete and technical), multi addicted (yes/no), murderer (yes/no), age in years, number of persons living with him, family incomes (USD) and number of months living in the street.

- In 2017, of 616 adolescents who were admitted to the institution the $82.3 \%$ entered by theft qualified, $5.3 \%$ homicide, $6 \%$ attempted homicide, $1.49 \%$ violation and $4.87 \%$ others.

- The $17.37 \%$ don't consume psychoactive substances, the $47.72 \%$ consume marihuana, $4.05 \%$ crack, $0.97 \%$ glues, $8.44 \%$ cigarette, $4.05 \%$ alcohol, $17.37 \%$ other types of drugs.

- The $14.61 \%$ living with father and mother, $73.05 \%$ live only with his mother, $8.76 \%$ live only with his father, $1.78 \%$ live with his grandparents, $1.62 \%$ with others and the $0.16 \%$ alone.

- The familiar income of the $34.09 \%$ is less than 1 S.M.L.V (240 USD), $51.46 \%$ live with 1 S.M.L.V (240 USD), $14.44 \%$ between 1 and 2 S.M.L.V (480 USD).

The classification of the dangerousness level was performed taking into account the following criteria, which were validated by the psychosocial teams of the SAC:

- High dangerous level: single marital status, incomplete primary education, multi addict, murderer, more than 14 years, more than 6 months living in the street, more than five persons in the household, family income below to 1 SMLV (240 USD)

- Medium dangerous level: single marital status, incomplete primary education, multi addict, murderer, more than 14 years, less than 5 people in the home, family income equal to 1 SMLV (240 USD), less than 6 months living in the street.

- Low dangerous level: single marital status, incomplete secondary education, consumer, not murderer, less than 14 years, three people in the home, family income greater than 1 and less than 2 SMLV (480 USD), zero months living in the street.

- Null dangerous level: single marital status, complete secondary education, not a consumer, not murderer, less than 14 years, less than three people in the home, higher family incomes to 1.5 SMLV (360 USD) and less than or equal to 2 SMLV (480 USD), zero months living in the street.

Profiled the database of adolescents who were admitted to the SAC in the year 2017 in four groups according to their dangerousness level (high, medium, low and null). The RBFNN developed using data from the predictive variables to predict the membership of adolescents to one of the four groups. The independent variable in the model was the dangerousness level, the factors were the schooling level, marital status, number of months living 
in the street and number of psychoactive substances that consumes. The covariates were the age in years and the number of persons living with him.

\section{Results}

This section, summarize the collected data and the analysis performed on those data. Table 1, presents the summary of the processing cases, 400 adolescents were allocated to the training sample, 153 to the test sample and 63 to the reserved sample. Is not excluded any adolescent of the analysis.

Table 1. Processes cases summary

\begin{tabular}{|c|c|c|}
\hline & $N$ & Percentage \\
\hline Example & 400 & $64,9 \%$ \\
\hline Test & 153 & $24,8 \%$ \\
\hline Reserve & 63 & $10,2 \%$ \\
\hline Sample & 616 & $100 \%$ \\
\hline Exclude & 0 & \\
\hline Total & 616 & \\
\hline
\end{tabular}

Table 2, presents the ANN information, it is useful to ensure that specifications are correct:

Table 2. ANN information

\begin{tabular}{cccc}
\hline & Factors & 1 & Marital status \\
& & 2 & Schooling level \\
\cline { 2 - 4 } Input layer & Co-variables & 1 & Age in years \\
& & 2 & Years in the current address \\
& & 3 & Familiar incomes (USD) \\
& & 4 & Number of people in household \\
\cline { 2 - 4 } Hidden layer & Number of units & & 11 \\
& & & Standardized corrected \\
& & & $2^{a}$ Determined by the testing data \\
& criterion: The "best" number of \\
& & & hidden units is the one that yields the \\
Output layer & smallest error in the testing data \\
\hline & Activation function & Softmax (Tiňo, 2009) \\
& Dependent variables & Dangerousness level \\
& Number of units & 4 \\
& Activation function & Identity \\
& Error function & Sum of squares \\
\hline
\end{tabular}

Table 3, presents the summary information about the results of the training, the test and the implementation of the network end to the reserved sample. Shows the sum of quadratic errors because they always used for networks RBF. This is the error function that the network tries to minimize during training and testing.

Table 3. Model summary

\begin{tabular}{ccc}
\hline & Sum of squares error & 144,362 \\
Training & $\%$ incorrect prognostics & $65,3 \%$ \\
& Preparation time & $0: 00: 00,91$ \\
\hline \multirow{2}{*}{ Test } & Error of sum squared & $51,678 \mathrm{a}$ \\
& $\%$ incorrect prognostics & $65,7 \%$ \\
\hline Reserve & $\%$ incorrect prognostics & $67,1 \%$ \\
\hline
\end{tabular}


Table 4, presents the practical results of the network. For each case, the predicted response is the category with the greatest pseudo-probability predicted by the model. The diagonal values of the cells are the correct predictions. The values outside the diagonal are the incorrect predictions.

Table 4. Dangerousness classification

\begin{tabular}{ccccccc}
\hline \multicolumn{1}{c}{ Example } & Observed & High & Medium & Low & Null & Global \% \\
\hline \multirow{5}{*}{ Training } & High & 63 & 0 & 24 & 25 & $56,3 \%$ \\
& Medium & 39 & 0 & 24 & 12 & $0,0 \%$ \\
& Low & 34 & 0 & 57 & 18 & $52,3 \%$ \\
& Null & 36 & 0 & 29 & 29 & $30,9 \%$ \\
& Global \% & $43,0 \%$ & $0,0 \%$ & $36,0 \%$ & $21,0 \%$ & $37,3 \%$ \\
\hline \multirow{5}{*}{ Sample } & High & 24 & 0 & 6 & 7 & $64,9 \%$ \\
& Medium & 9 & 0 & 11 & 16 & $0,0 \%$ \\
& Low & 12 & 0 & 19 & 9 & $47,5 \%$ \\
& Null & 7 & 0 & 8 & 15 & $50,0 \%$ \\
& Global \% & $36,4 \%$ & $0,0 \%$ & $30,8 \%$ & $32,9 \%$ & $40,6 \%$ \\
\hline \multirow{5}{*}{ Reserve } & High & 12 & 0 & 7 & 5 & $50,0 \%$ \\
& Medium & 5 & 0 & 6 & 5 & $0,0 \%$ \\
& Low & 8 & 0 & 5 & 5 & $27,8 \%$ \\
& Null & 3 & 0 & 4 & 8 & $53,3 \%$ \\
& Global $\%$ & $38,4 \%$ & $0,0 \%$ & $30,1 \%$ & $31,5 \%$ & $34,2 \%$ \\
\hline
\end{tabular}

Given the observed data, the model that does not include any predictor classified to all adolescents in the medium dangerousness level. Therefore, this model would be correct $137 / 616=22.24 \%$ of the times. The RBFNN get a $15.05 \%$ more, i.e. $37.3 \%$ of adolescents. The developed model is good to identify adolescents with a high, low and null dangerousness level. However, works exceptionally bad for classifying adolescents with a medium dangerousness level. The reserved sample $(n=63)$ helps to validate the model. In this case, the model correctly classified $39.7 \%$ of cases. Although the sample reserved is quite small, it suggests that the model is correct.

Note. As future work raises the need to develop simulation agents based models which will see the behavioral evolution of young offenders in the medium and long term, under different types of therapeutic pedagogical treatments.

\section{Conclusions}

This paper presents the training of a RBFNN to classify the adolescent offenders of the law according to their dangerousness level. This classified correctly the $39,7 \%$ of the reserved sample. Although the sample reserved is quite small, it suggests that the model is correct about three out of every five times. The ANN developed is particularly good for identifying adolescents with high and low dangerousness level. The schooling level, the number of psychoactive substances and homicides are the most significant predictors for determining the dangerousness level of young offenders of the law. The RBFNN developed is exceptionally bad for classifying adolescents with a medium dangerousness level. The sample reserved $(n=63)$ helps to validate the model. In this case, the model correctly classified $39.7 \%$ of cases. Although the sample reserved is quite small, it suggests that the model is correct.

\section{References}

Alcorn, T. (2016). Rethinking mental health care for young offenders. The Lancet, 383(9925), 1283-1284. https://doi.10.1016/S0140-6736(14)60449-9

Arliansyah, J. \& Hartono, Y. (2018). Trip attraction model using radial basis function neural networks. Procedia Engineering, 1, 445-451. https://doi.10.1016/j.proeng.2018.11.117

Eccleston, L. \& Ward, T. (2004). Chapter 5 - Assessment of Dangerousness and Criminal Responsibility. In W. T. O'Donohue \& E. R. Levensky (Eds.), Handbook of Forensic Psychology (pp. 85-101). San Diego: 
Academic Press. http://dx.doi.org/10.1016/B978-012524196-0/50006-1

González, M. J. C. (2010). 31 - Supuestos de peligrosidad criminal: Aspectos médico-forenses. In M. J. C. González (Ed.), Manual Práctico de Psiquiatría Forense (Primera edición) (Primera ed. 349-365). Elsevier España. http://dx.doi.org/10.1016/B978-84-458-2042-1.50031-3

Guan, X., Zhu, Y. \& Song, W. (2016). Application of $\{R B F\}$ neural network improved by peak density function in intelligent color matching of wood dyeing. Chaos, Solitons \& Fractals, -. http://dx.doi.org/10.1016/j.chaos.2016.02.015

Gubana, A. (2018). State-of-the-Art Report on high reversible timber to timber strengthening interventions on wooden floors. Construction and Building Materials, 97, 25-33. http://dx.doi.org/10.1016/j.conbuildmat.2018.06.035

Henao, G. J. C. \& Suárez, L. M. M. (2013). Aplicación del Modelo ANFIS para predicción de series de tiempo. Revista Digital de La Facultad de Ingenierías "Lámpsakos", 1(9), 12-25. https://doi.org/10.21501/21454086.927

Iliyas, S. A., Elshafei, M., Habib, M. A. \& Adeniran, A. A. (2013). \{RBF\} neural network inferential sensor for process emission monitoring. Control Engineering Practice, 21(7), 962-970. http://dx.doi.org/10.1016/j.conengprac.2013.01.007

Ochoa, J. (2014). La intervención en los menores infractores de Medellín. Corporación Universitaria Minuto de Dios.

Peay, J. (2009). Mental illness, dangerousness and protecting society. Psychiatry, 8(12), 490-492. http://dx.doi.org/10.1016/j.mppsy.2009.09.013

Plume, M. L. (2003). \{SPSS\} Statistical Package for the Social Sciences). In H. Bidgoli (Ed.), Encyclopedia of Information Systems (pp. 187-196). New York: Elsevier. http://dx.doi.org/10.1016/B0-12-227240-4/00166-0

Pollock, J. M. (2012). Chapter 13 - Prisons and Jails. In J. M. Pollock (Ed.), Crime and Justice in America (Second Edition) (Second Edi., pp. 329-361). Boston: Anderson Publishing, Ltd. http://dx.doi.org/10.1016/B978-1-4377-3512-3.00013-5

Pons, J. \& Buelga, S. (2011). Factores Asociados al Consumo Juvenil de Alcohol: Una Revisión desde una

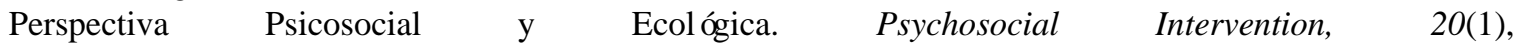
75-94.http://dx.doi.org/10.5093/in2011v20n1a7

Rodríguez, E. E. (2003). Valoración De La Peligrosidad Criminal (Riesgo- Violencia ) En Psicología Forense . Aproximación Conceptual E Histórica. Psicopatología Clínica Legal Y Forense, 3(2), 45-64. Retrieved from http://masterforense.com/pdf/2003/2003art10.pdf

Tiňo, P. (2009). Bifurcation structure of equilibria of iterated softmax. Chaos, Solitons \& Fractals, 41(4), 1804-1816. https://doi.10.1016/j.chaos.2008.07.026

Vilariño, M., Amado, B. G. \& Alves, C. (2013). Menores infractores: un estudio de campo de los factores de riesgo. Anuario de Psicología Jurídica, 23(1), 39-45. https://doi.http://dx.doi.org/10.5093/aj2013a7

Yu, H. \& Xie, T. (2011). Advantages of radial basis function networks for dynamic system design, IEEE Transactions on, 58(12), 5438-5450. https://doi.10.1109/TIE.2011.2164773

\section{Copyrights}

Copyright for this article is retained by the author(s), with first publication rights granted to the journal.

This is an open-access article distributed under the terms and conditions of the Creative Commons Attribution license (http://creativecommons.org/licenses/by/4.0/). 